\title{
Investigation of Inferential Skills in School Going Preadolescents
}

\author{
Grace Sara Abraham ${ }^{1}$, Lakshmy Rajasekharan², Sabitha Anirudhan ${ }^{3}$ \\ ${ }^{1}$ Head of the Department, Institute of Speech and Hearing, Marthoma College of Special Education, Kerala \\ University of Health Sciences, Kasargod, Kerala, India. \\ ${ }^{2}$ Research Coordinator, Institute of Speech and Hearing, Marthoma College of Special Education, Kerala \\ University of Health Sciences, Kasargod, Kerala, India. \\ ${ }^{3} \mathrm{PG}$ student, Institute of Speech and Hearing, Marthoma College of Special Education, Kerala University of \\ Health Sciences, Kasargod, Kerala, India \\ Corresponding Author: Lakshmy Rajasekharan
}

\begin{abstract}
Inferential skill plays an important part in the comprehension of language and enhances educational performance of school-aged children. We examined the role of age, gender and scholastic performances in inferential skills of preadolescent students attending English medium school (age range 8 to 12 years). In order to compare the inferential skills across age, gender and scholastic performances, t-test was used. There was a steady increase in the inference skills of students with increasing age. The inferential skills of male students were found to be better than female students. Students with above average scholastic performance made more inferences than students with below average scholastic performance. The higher scores in inferential skills across these three domains could be due to better vocabulary, reading comprehension and world knowledge. This paper emphasizes on the importance of inferential skills in educational success. It identifies the key factors influencing the inferential skills and the need to work on them by the school-based speech language pathologists (SLP).
\end{abstract}

Keywords: Inferential skill, educational success, scholastic performance, preadolescent, inference.

\section{INTRODUCTION}

Human beings make inferences based on their experiences. Making inferences also depend on a person's ability to use non-linguistic cues to understand linguistic utterances. "An inference is the ability to connect what is in the text with what is in the mind to create an educated guess" (Beers, 2003). ${ }^{1}$ Making inferences can be a simple or complex task. This depends on many factors like understanding subtle messages, vocabulary used by the writer and the background knowledge. Inference skills have an active role to play in language comprehension especially in school-aged children. Language comprehension helps in the scholastic performance of school going children. This in turn makes the inference skill crucial for school going children. "It is a complex process that involves more than understanding each word, morpheme and sentence" (Paul, 2000). ${ }^{2}$ For decoding a message, children must take into account the linguistic and non-linguistic cues of the speaker, their own knowledge of the world and the speaker's. In addition, they must develop the ability to read between the lines. According to Gineste \& LeNy, 2002, one should have the ability to read between the lines and should take into consideration certain elements which are not precisely spoken by the speaker. ${ }^{3}$ 


\subsection{LITERATURE REVIEW}

$$
\text { McKoon and Ratcliff }
$$
described inference as "any piece of information that is not explicitly stated in a text". According to them there is a huge range of inferences. Graesser, Singer, and Trabasso (1994) have identified 13 classes of inferences, ranging from simple to complex and elaborative. ${ }^{5}$ Inference can be as simple as associating a pronoun with a previously mentioned noun. It can also be as complex as understanding a subtle message, conveyed through a particular word or a facial expression. Suh and Trabasso (1993) in their study found that comprehension of a text is done by making a representation of that text which requires integration of the information across the sentences. ${ }^{6}$ This happens when the individual connects the text with his or her experiences and relevant knowledge. The comprehension of the text that is read happens when inferences are made. In other words, without making inferences an individual cannot understand the text or the meaning implied by the other person.

Inference forms the foundation of language comprehension and is also considered as a higher cognitive skill. It is also a prerequisite for thinking. Inferencing abilities begin developing at birth. Children use inference skills in everyday situations. During the preschool period, children view language primarily as a means of communication. They do not focus on the manner in which language is conveyed (Van Kleech, 1982). ${ }^{7}$ During the school age years, the child begins to reflect on language as a decontextualized object. The development of metalinguistic abilities is most obvious during middle childhood, between about 5 and 8 years of age. This metalinguistic ability allows us to infer. The production of language is a linguistic function whereas the evaluation of language is a metalinguistic function. A child would have acquired the ability to comprehend and express oral language in a variety of contexts by the time he or she attends school (Snow, 1983). ${ }^{8}$ Inference skills were associated with later reading achievement (Perfetti, 1987). ${ }^{9}$ This was also considered to provide the base for the acquisition of reading comprehension skills. Therefore, Inferencing is an important skill that needs to be acquired and facilitated in school.

\subsection{Need and significance for the study.}

The educators should mainly focus on inference skills (Hansen ,1981). ${ }^{10}$ This is because the different type of inference skills is learned from primary school level. The ability of the young children to infer helps them in better comprehension and make them capable to enter the intermediate grades. Preadolescent children have to face a lot of challenges in terms of curriculum, vocabulary, new teachers and their teaching style as they shift from primary to secondary school. Inferencing skills will help them in overcoming most of these challenges. These skills can help them in the real world too. It is important to nurture the inference skills in school going children. Hence the need to study the different factors that affect inference skills. This will enable the school-based speech pathologist to bridge the gap in inference skills between childhood and adolescence.

\subsection{Aim of the study:}

(i) To compare the inferential skills across age and gender.

(ii) To analyze the effect of scholastic performance on inferential skills.

\section{METHOD}

This study was carried out in 5 phases. On the basis of age, the subjects were grouped into $\mathrm{G} 1$ and $\mathrm{G} 2$ with each group consisting of 60 participants respectively. G 1 included students under the age range 8 to 9.11 years and G2 included students under the age range 10 to 11.11 years of age. Mean, standard deviation and median of each domain was calculated for both groups. The t- test was used for the comparison of two groups. 
Phase 1: Development and validation of grade level assessment checklist. This checklist was used to group the participants based on their academic performance.

Phase 2: Administration of Language Experience and Proficiency- Questionnaire (LEAP-Q) to screen and select participants for the study.

Phase 3: Administration of the grade level assessment checklist for grouping the subjects into above and below average academic performance.

Phase 4: Administration of Assessment tool for inferencing skill. This assessment tool for inferencing skills consists of 10 domains namely Location inferences, agent inferences, time inferences, action inferences, instrument inferences, category inferences, object inferences, cause-effect inferences, problem solution inferences, feeling- attitude inferences. This tool was used to find the age and gender differences in inference skills and the effect of scholastic performance on inference skills

Phase 5: Statistical Analysis

\subsection{Participants:}

The study included a total number of 120 preadolescents in the age range 8 to 12 years. As this test was conducted in English language, preadolescent students attending English medium school since lower primary classes were included for the study. Children who are mentally or physically challenged (sensory loss, motor deficits) and with language learning disability were excluded from the study.

Description of group distribution is shown in the below given flowchart (Figure 1,2 and 3 )

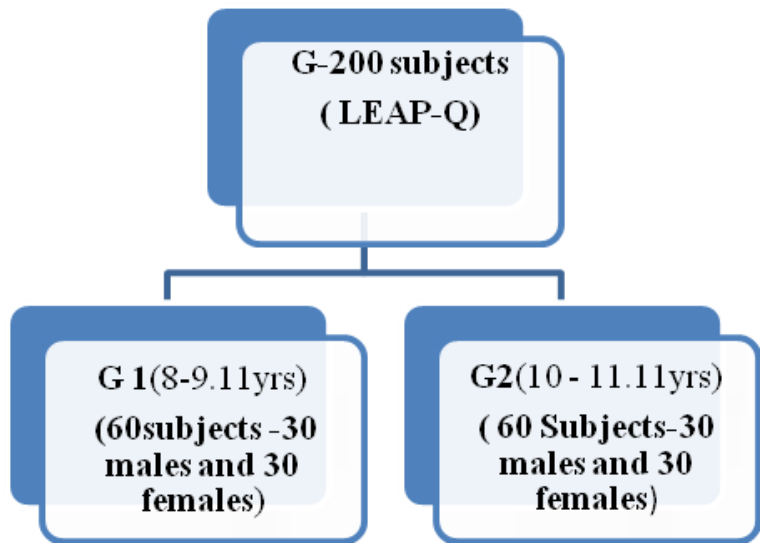

Figure 1: Group distribution based on age range

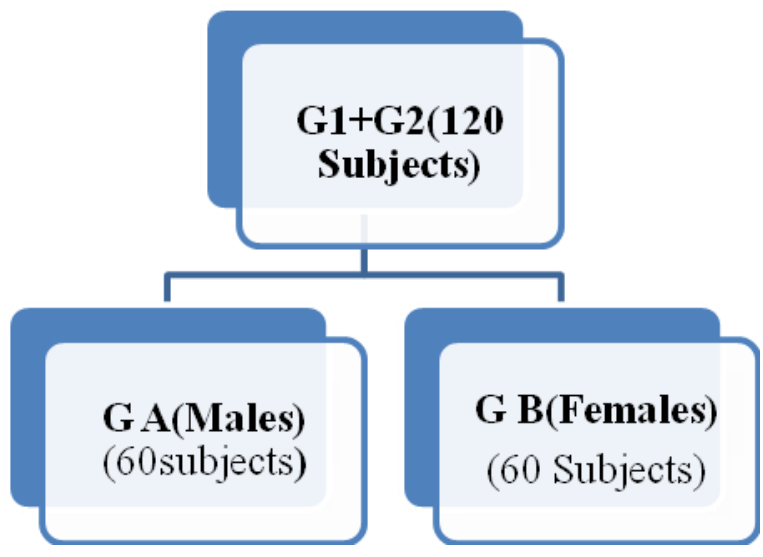

Figure 2: Group distribution based on gender

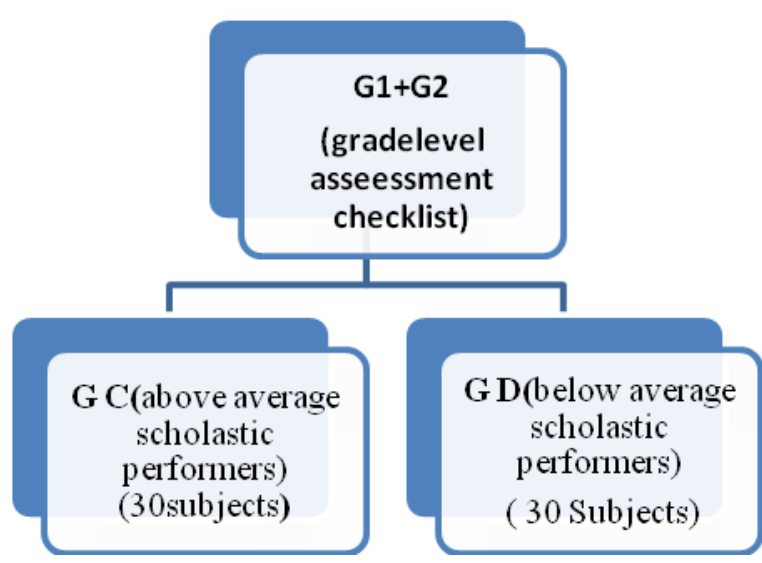

Figure 3: Group distribution based on scholastic performance

\subsection{Procedure}

The first phase of the study involved the development of Grade Level Assessment Checklist to group the students on the bases of academic performance. The entire checklist was divided into part A and part B. Part A included demographic data, 
general health and associated health conditions. Part B addresses academic performance based on ratings. A 3-point rating scale (0-2) is used for scoring with a total score of 60 . The grade level assessment checklist was given to 10 speech language pathologists for checking the validity.

The second phase involved the administration of LEAP-Q and the Grade Level Assessment Checklist. LEAP-Q was given to 200 randomly selected participants of grade 3 to grade 7 of four CBSE schools (from Kasaragod and Alappuzha districts). LEAP-Q was used to screen and select the students who were proficient in English language.120 such students were selected. In the third phase Grade level Assessment Checklist were administered to these students to assess their general academic performance. The student's yearly progress reports along with teacher's feedback about their general academic performance were also taken into consideration. Based on the results the total sample size selected for the study was $120(\mathrm{G}=120)$. The fourth phase consists of administration of Assessment tool for inferencing skill. The assessment tool for inference skills consists of 10 domains namely Location inferences, agent inferences, time inferences, action inferences, instrument inferences, category inference, object inferences, cause-effect inferences, problem solution inferences, feeling- attitude inferences.

Each domain included 6 questions used to assess the participant's inferencing abilities. The responses were scored as follows:

1. Wrong inference or no inference - 0

2. Partial inference or general inference 1(Half score)

3. Correct inference -2 (Full Score)

This tool was used to find the age and gender differences in inference skills, effect of scholastic performance on inference skills. The fifth and final phase of the study was the analysis of the obtained data. The mean and standard deviation for the values has been derived for all the groups across all the domains of the standardised test material. Independent t-test was employed to determine the difference between each group across each domain.

\section{RESULTS AND DISCUSSION}

The first objective of the study was to find out the effect of age and gender on inferential skills of the preadolescents. The second objective was to find out the effect of scholastic performances on inferential skills. The 120 participants were divided into two groups based on age, gender, scholastic performances. The $\mathrm{t}$ - test was employed to find significant differences across these three categories.

\subsection{Age difference:}

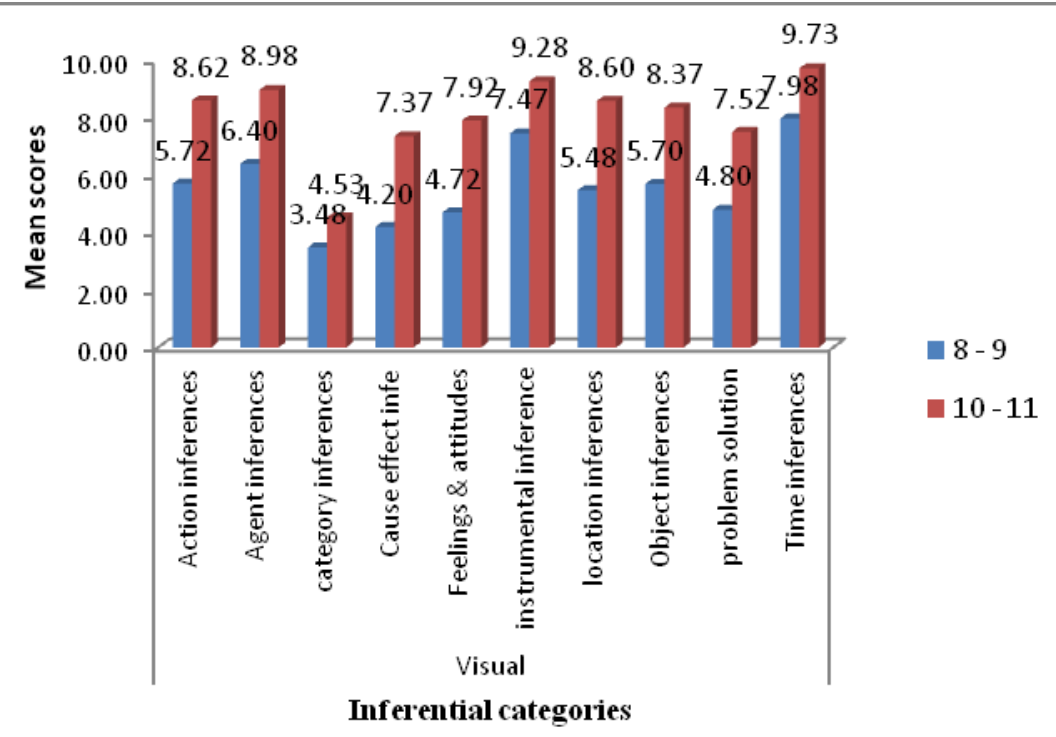

Figure 4: Mean scores of G1 (8-9.11 years) and G2 (10-10.11years) across ten domains of inferential skills. 
Ten inferential categories were analyzed across two age groups G1 (8yrs to $9.11 \mathrm{yrs}$ ) and G2 (10yrs to $11.11 \mathrm{yrs}$ ). Mean, standard deviation and median of each domain were calculated for both groups. The $t$ - test was used for the comparison of two groups.

Descriptive statistics (figure 4) indicates that in group G1 when compared to all other domains, Time inference domain showed the higher mean score of 7.98 and category inference domain showed the lower mean score of 3.48. In group G2, when compared to other domains time inference (mean score 9.73) and instrumental inference domain (mean score 9.28) showed higher mean scores and category inference domain showed lower mean scores of 4.53 .

Table 1. Mean (M), median, standard deviation (SD) and t-test results of G1 (8-9.11 years) and G2 (10-11.11 years) across ten domains of inferential skills, HS (Highly significant).

\begin{tabular}{|c|c|c|c|c|c|c|c|c|c|c|}
\hline Domains & Age & $\mathbf{N}$ & Minimum & Maximum & Mean & Std. Deviation & Median & t-value & $\mathbf{P}$ & \\
\hline \multirow[t]{2}{*}{ Action inferences } & $8-9$ & 60 & 0 & 10 & 5.72 & 2.91 & 6.00 & 5.48 & .000 & $\mathrm{HS}$ \\
\hline & $10-11$ & 60 & 0 & 12 & 8.62 & 2.89 & 9.00 & & & \\
\hline \multirow[b]{2}{*}{ Agent inferences } & $8-9$ & 60 & 0 & 12 & 6.40 & 3.59 & 6.50 & 4.49 & .000 & $\mathrm{HS}$ \\
\hline & $10-11$ & 60 & 1 & 12 & 8.98 & 2.64 & 10.00 & & & \\
\hline \multirow[b]{2}{*}{ category inferences } & $8-9$ & 60 & 0 & 12 & 3.48 & 2.27 & 4.00 & 2.28 & .024 & Sig \\
\hline & $10-11$ & 60 & 0 & 11 & 4.53 & 2.75 & 4.00 & & & \\
\hline \multirow[b]{2}{*}{ Feelings \& attitudes } & $8-9$ & 60 & 0 & 12 & 4.72 & 2.52 & 4.00 & 6.34 & .000 & $\mathrm{HS}$ \\
\hline & $10-11$ & 60 & 2 & 12 & 7.92 & 2.99 & 8.00 & & & \\
\hline \multirow[b]{2}{*}{ instrumental inference } & $8-9$ & 60 & 0 & 12 & 7.47 & 2.80 & 8.00 & 3.72 & .000 & $\mathrm{HS}$ \\
\hline & $10-11$ & 60 & 4 & 12 & 9.28 & 2.54 & 10.00 & & & \\
\hline location inferences & $8-9$ & 60 & 0 & 10 & 5.48 & 2.94 & 6.00 & 6.70 & .000 & $\mathrm{HS}$ \\
\hline problem solution & $10-11$ & 60 & 0 & 12 & 7.52 & 3.09 & 9.00 & & & \\
\hline \multirow[b]{2}{*}{ Time inferences } & $8-9$ & 60 & 0 & 12 & 7.98 & 3.82 & 10.00 & 2.86 & .005 & $\mathrm{HS}$ \\
\hline & $10-11$ & 60 & 0 & 12 & 9.73 & 2.81 & 10.00 & & & \\
\hline \multirow[b]{2}{*}{ TOTAL } & $8-9$ & 60 & 4 & 93 & 52.98 & 21.02 & 54.50 & 7.32 & .000 & $\mathrm{HS}$ \\
\hline & $10-11$ & 60 & 24 & 113 & 80.78 & 20.57 & 88.00 & & & \\
\hline
\end{tabular}

As shown in table -1 t-test results indicate that there is a statistically significant difference between group G1 and G2 across all the 10 domains of inferential skills. From the figure 4, it is clear that G1 showed lower scores for all the 10 domains of the inferential test material than G2. These statistical test results show that inferential ability increases with age. This betterment of inferential skill with age is supported by many other studies (Oakhill and Cain, 2003; Paris, 1976; Paris, Lindauer and Cox, 1977). ${ }^{11-13}$ Increase in inferential skills can be attributed to the factors such as decoding skills, development of vocabulary, syntactic development, understanding text structure, identification of main ideas etc. It has been found that as age and experience increase the ability to decode, world knowledge, and vocabulary increases. As age increases children can identify the main idea of the text by decoding the meaning of the syntactic structures in the text. Young children can infer better with frequent prompting. In fact, they can infer the same way an older child can make inferences with the help of prompts. As world knowledge increases with age, the inference skills also increase with age (Casteel \& Simpson, 1991). ${ }^{14}$

In the study done by Filiatrault, Bouchard, Trudeau\& Demarrias (2016) children aged 3-6 years of age it was found that inferential comprehension in the context of a story emerges at 3 years of age. ${ }^{15}$ At the age of 4 , Children could infer the problem of the story and also provided predictions. Children of age 5-6 years were better at making inferences about the goal of the main character, the attempts at problem solving, and the resolution of the story. This study supports the notion that inferential 
skills develop with increasing age. The number of inferences increases when the standard increases, indicating that inferential ability increases with age and with standard (Dalvi,2015). ${ }^{16}$

One of the major factors that may account for the improvement in inferential skill that is found with age is the memory. Memory improves with age. Another factor for the differences in making inferences due to age is comprehension abilities. Another factor that increases with age is world knowledge. Also, recall of text recall increases the world knowledge and which in turn increases with age (Brown and Smiley,
1977; Mandler and Johnson, 1977). ${ }^{17-18}$ All these factors contribute to the increase of inference skill with age in children.

\subsection{Gender difference:}

On the basis of gender, the 120 subjects were grouped into group GA (males) and Group GB (females) with each group consisting of 60 participants respectively. Mean and standard deviation of each domain was calculated for groups. The t-test was employed to determine the significant difference between groups GA (males) and GB (females).

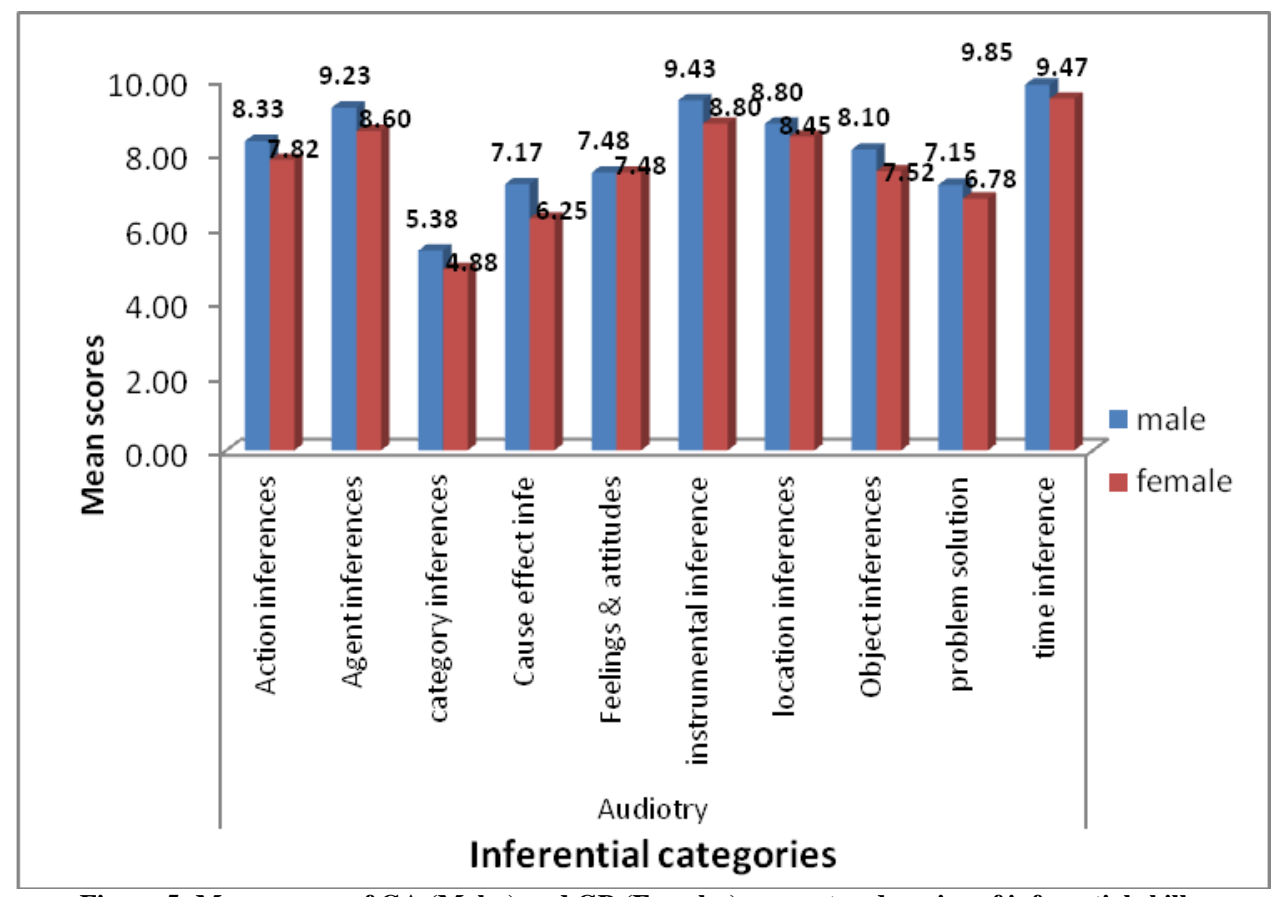

Figure 5: Mean scores of GA (Males) and GB (Females) across ten domains of inferential skills.

Descriptive statistics show that in group GA (males) when compared to other domains Time inference domain (mean score 9.85) and agent inference domain (mean score 9.23) showed higher mean value and category inference domain showed a lower mean score of 5.38. In group GB (Females), when compared to other domains Time inference domain showed the higher mean score of 9.47 and category inference domain showed the lower mean score of 4.88 .

Table 2: - Mean (M), median, standard deviation (SD) and t-test results of GA (Males) and GB (Females) across ten domains of inferential skills.

\begin{tabular}{|c|c|c|c|c|c|c|c|c|c|c|}
\hline Domains & Sex & $\mathbf{N}$ & Minimum & Maximum & Mean & Std. Deviation & Median & t value & $\mathbf{P}$ & \\
\hline \multirow[t]{2}{*}{ Action Inferences } & Male & 60 & 2 & 12 & 8.33 & 2.608 & 9.0 & 1.007 & .316 & NS \\
\hline & Female & 60 & 2 & 12 & 7.82 & 3.000 & 8.0 & & & \\
\hline \multirow[t]{2}{*}{ Agent inferences } & Male & 60 & 3 & 12 & 9.23 & 2.638 & 10.0 & 1.284 & .202 & NS \\
\hline & Female & 60 & 2 & 12 & 8.60 & 2.763 & 9.5 & & & \\
\hline \multirow[t]{2}{*}{ category inference } & Male & 60 & 0 & 11 & 5.38 & 2.498 & 5.0 & 1.137 & .258 & $\mathrm{NS}$ \\
\hline & Female & 60 & 1 & 12 & 4.88 & 2.315 & 5.0 & & & \\
\hline \multirow{2}{*}{$\begin{array}{l}\text { Cause effect } \\
\text { inferences }\end{array}$} & Male & 60 & 2 & 12 & 7.17 & 3.065 & 7.0 & 1.750 & .083 & $\mathrm{NS}$ \\
\hline & Female & 60 & 0 & 12 & 6.25 & 2.659 & 6.0 & & & \\
\hline
\end{tabular}




\begin{tabular}{|c|c|c|c|c|c|c|c|c|c|c|}
\hline \multicolumn{11}{|c|}{ Table 2 Continued... } \\
\hline \multirow[t]{2}{*}{ Feelings \& attitudes } & Male & 60 & 4 & 12 & 7.48 & 2.613 & 6.0 & .000 & 1.000 & NS \\
\hline & Female & 60 & 4 & 12 & 7.48 & 2.432 & 6.0 & & & \\
\hline \multirow[t]{2}{*}{ instrumental inference } & Male & 60 & 4 & 12 & 9.43 & 2.382 & 10.0 & 1.428 & .156 & NS \\
\hline & Female & 60 & 4 & 12 & 8.80 & 2.476 & 9.5 & & & \\
\hline \multirow[t]{2}{*}{ location inferences } & Male & 60 & 2 & 12 & 8.80 & 2.576 & 9.0 & .747 & .456 & NS \\
\hline & Female & 60 & 2 & 12 & 8.45 & 2.554 & 10.0 & & & \\
\hline \multirow[t]{2}{*}{ Object inferences } & Male & 60 & 3 & 12 & 8.10 & 2.549 & 8.0 & 1.134 & .259 & NS \\
\hline & Female & 60 & 2 & 12 & 7.52 & 3.061 & 8.0 & & & \\
\hline \multirow[t]{2}{*}{ problem solution } & Male & 60 & 2 & 12 & 7.15 & 2.654 & 7.0 & .684 & .495 & NS \\
\hline & Female & 60 & 0 & 12 & 6.78 & 3.195 & 6.5 & & & \\
\hline \multirow[t]{2}{*}{ Time inferences } & Male & 60 & 2 & 12 & 9.85 & 2.496 & 10.0 & .789 & .431 & NS \\
\hline & Female & 60 & 2 & 12 & 9.47 & 2.813 & 10.0 & & & \\
\hline \multirow[b]{2}{*}{ TOTAL } & Male & 60 & 37 & 112 & 80.90 & 18.606 & 83.0 & 2.020 & .046 & Sig \\
\hline & Female & 60 & 33 & 111 & 73.60 & 20.923 & 74.0 & & & \\
\hline
\end{tabular}

Figure 5 shows the mean scores of scores of GA and GB and Table 2 shows the mean, standard deviation and t-test results. The t-test was carried out for the comparison of gender (Table 2). The overall performance shows a significant difference between males and females that is the overall performance of males is better than females. This can be attributed to better reading comprehension of boys than girls (Martinez 2013). ${ }^{19}$ The reasons cited by Martinez (2013) ${ }^{19}$ for the males' superiority in inferences skills is that the male students gain immense knowledge on the topic they are interested in and read a lot of varied informative literature when compared to their female counterparts. Hence, their ability to infer is better than females who show more interest in a certain than a variety of topics. They are not able to infer correctly when given unfamiliar text. This could be because the male and female children taken for the present study were not matched equally based on their interest on different topics. There are studies that show no significant differences in inference skills between male and female students (Dalvi, 2015). ${ }^{16}$ The influence of gender needs to be studied furthermore.

\subsection{Effect of scholastic performance}

On the basis of grade level assessment, the participants were grouped into two groups, GC and GD. GC included 30 participants of above average scholastic performance and GD included 30 participants of below average scholastic performance. Mean and standard deviation of overall performance on inferential skill were calculated for the two groups. The ttest was employed to determine the significant differences between these two groups.

Descriptive analysis was carried out for both groups and from the Figure 6, it is clear that the mean scores of below average scholastic performers are lower than the above average scholastic performers. In visual modality the overall mean score for the inference skills of below average students is 31.9333 and above average students is 96.6129

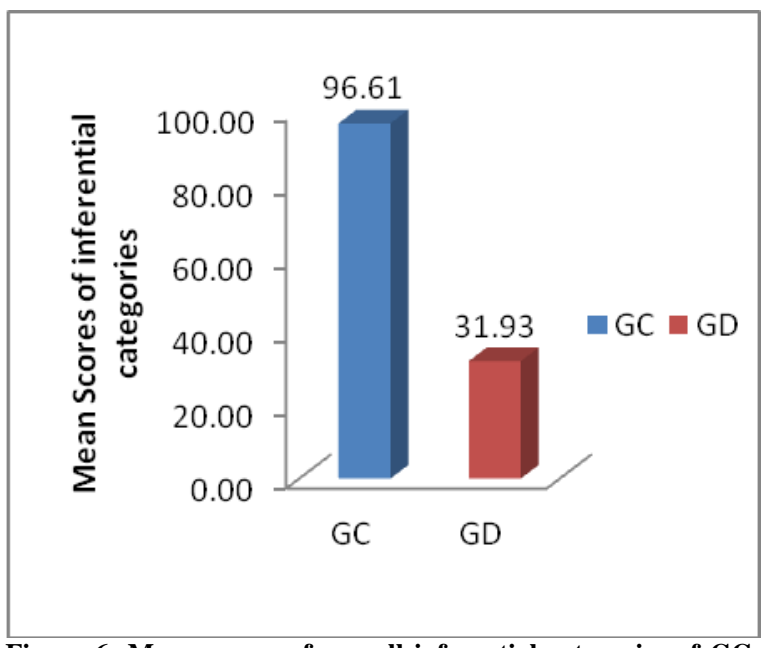

Figure 6: Mean scores of overall inferential categories of GC (above average scholastic performers) and GD (below average scholastic performers).

t-test

The t-test results from table 3 indicate highly significant differences between GC and GD. This indicates a positive correlation between academic performance and inferential skills. Children with above average scholastic performance have better decoding skills, memory, vocabulary and knowledge of syntactic 
structures (Hansen and Pearson,1983; Olson 1985). ${ }^{20-21}$ They have better reading comprehension. They are better readers and are good at understanding metalinguistic cues. Thus, their inferencing skills are better than children with below average scholastic performance.

Table 3: - Overall Mean (M), standard deviation (SD) and t-test results of GC (Above average scholastic performers) and GD (Below average scholastic performers) in visual modality.

\begin{tabular}{|l|l|l|l|l|l|l|}
\hline & & Mean & Standard Deviation & T & P & \\
\hline Visual modality & Poor & 31.9333 & 11.88431 & 26.877 & .000 & HS \\
\cline { 2 - 5 } & Good & 96.129 & 6.09195 & & & \\
\hline
\end{tabular}

\section{CONCLUSION}

Comprehension of language is an integral part of communication. We make inference to comprehend what is said, read or written. Inferences are made by using non-linguistic experiences to understand linguistic utterances i.e., we have to consider the emotions, facial expressions, intentions of the speaker along with what they speak. Our knowledge of the world also helps us to make inferences. Since inference skills improve language comprehension it is very important in the education of children (Hansen,1981). ${ }^{10}$ Improving inference skills at primary school age will equip children with better comprehension and make the transition from primary to secondary school smooth. This should be the main focus of teachers, school based SLPs etc. Less is known about the different factors that affect inference skills in a growing child. The effect of factors like age, gender, scholastic performance of a child on inference skills were tested to obtain data that can enable the educators to improve inference skills in school going children.

The present study reveals that inference skills are highly influenced by age, gender, and academic performance of pre-adolescent children. It was found that as age increases there is an increase in the inferential skills of the participants. It also reveals that male students make more inferences than female students. Students of above average scholastic performers make more inferences compared to students of below average scholastic performers. This could be due to inadequate vocabulary building and reading comprehension. These grey areas need to be assessed and proper intervention should be given to make the inferencing skills better. This will in turn lead to educational success in school going children. It is very important to have a school based SLP who can identify the factors that lead to poor inferencing skills and can work on the same. Therefore, the evaluations and intervention by SLPs will be helpful for the school going children to develop their linguistic and metalinguistic skills. This can contribute to better scholastic performances by the children.

\section{Acknowledgement: None}

\section{Conflict of Interest: None}

\section{Source of Funding: None}

\section{Ethical Approval: Approved}

\section{REFERENCES}

1. Beers, K. (2003). When kids can't read: What teachers can do. Portsmouth, NH: Heinemann.

2. Paul, R. (2000). 'Putting things in context': literal and discourse approaches to comprehension assessment. Seminars in Speech and Language, 21, 247-254; quiz, 255.doi:10.1055/s- 2000-

3. Gineste, M. -D., \& Le Ny, J. F. (2002). Psychologie cognitive du langage: de la reconnaissance à la comprèhension. Paris: Dunod.

4. McKoon, G., \& Ratcliff, R. (1992). Inference during reading. Psychological Review,99, 440- 466.

5. Graesser, A. C., Singer, M., \& Trabasso, T. (1994). Constructing inferences during narrative text comprehension. Psychological Review, 101 (3), 371-395.

6. Suh, S., \& Trabasso, T. (1993). Inferences during reading: Converging evidence from 
discourse analysis, talk-aloud protocols and recognition priming. Journal of memory and Language, 32, 270-301

7. Van Kleech, A. (1982). The emergence of linguistic awareness: A cognitive frame work., Merrill-palmer Quarterly, 28, 237265).

8. Snow, C. E. (1983). Literacy and language: Relationships during the preschool years. Harvard Educational Review, 53, 165-189.

9. Perfetti, C. A. (1987). Language, speech, and print: Some asymmetries in the acquisition of literacy. In R. Horowitz \& S. J. Samuels (Eds.), Comprehending oral and written language (pp. 355-369). San Diego, CA: Academic Press.

10. Hansen, J. (1981). Inferential comprehension strategy for use with primary grade children. The Reading Teacher, 34, 665-669.

11. Oakhill, J., Cain, K., \& Bryant, P. (2003). The dissociation of single-word reading and text comprehension: Evidence from component skills. Language and Cognitive Processes, 18

12. (4), 443-468.

13. Paris, S., (1976). Children's memory for inferential relationships in prose. Child Development, 47, 660-668.

14. Paris, S., Lindauer, B., \& Cox, G. (1977). The development of inferential comprehension. Child Development, 48, 1728-1733.

15. Casteel, M. A., \& Simpson, G. B. (1991). Textual coherence and the development of inferential generation skills. Journal of Research in Reading, 14, 116-129.

16. Filiatrault-Veilleux, P., Bouchard, C., Trudeau, N., \&Desmarais, C. (2016). Comprehension of Inferences in a Narrative in 3- to 6-Year-Old Children. Journal of Speech Language and Hearing Research, 59(5), 1099. https://doi.org/10.1044/2016_JSLHR-L-150252

17. Dalvi, U., and Varsha, N. s., (2015). Study of Inferential Ability in Primary School Children. Language in India.Vol. 15

18. Brown, A., \& Smiley, S. (1977). Intrusion of a thematic idea in children's recall of prose. Child Development, 48 (1), 14541466.

19. Mandler, J., \& Johnson, N. (1977). Remembrance of things parsed: Story structure and recall. Cognitive Psychology, 9, 111-151.

20. Martinez, A. C. (2013). Analysis of the Effect of Content Familiarity and Gender on English as a Foreign Language Reading Comprehension by Spanish University Students University of Oviedo. Retrieved from January $\quad 4, \quad 2016$ http://www.ugr.es/ portalin/articulos/PL_nu mero2 1/5\%20\%20Ana\%20Cristina.pdf.

21. Hansen, J., \& Pearson, P. D. (1983). An instructional study: Improving the inferential comprehension of good and poor fourth-grade readers. American Psychological Association, 75, 821-829.

22. Olson, M. (1985). Text type and reader ability: The effects on paraphrase and textbased inference questions. Journal of Literacy Research, 17 (3), 199-214.

How to cite this article: Abraham GS, Rajasekharan L, Anirudhan S. Investigation of inferential skills in school going preadolescents. Int J Health Sci Res. 2021; 11(7):272-280. DOI: https://doi.org/10.52403/ijhsr.20210737 